\title{
PREVALENCIA DE VAGINOSIS BACTERIANA Y FACTORES ASOCIADOS EN VEINTE CIUDADES DEL PERÚ
}

\author{
Lorena López-Torres ${ }^{1, a}$, Marina Chiappe ${ }^{1, a}$, César Cárcamo ${ }^{1, b}$, Geoff Garnett², \\ King Holmes ${ }^{3, d}$, Patricia García ${ }^{1, e}$
}

\section{RESUMEN}

Objetivos. Determinar la prevalencia de vaginosis bacteriana (VB) y factores asociados en mujeres peruanas de 18 a 29 años de edad en 20 ciudades a partir de datos del proyecto PREVEN. Materiales y métodos. Estudio de tipo transversal, la definición de VB se realizó previa selección de una muestra de secreción vaginal en una lámina portaobjetos. Las láminas fueron teñidas usando la tinción Gram para ser observadas al microscopio usando el puntaje de Nugent, el diagnóstico de VB se aplicó a los puntajes 7-10. Se estimaron razones de prevalencias (RP) y sus intervalos de confianza al 95\% (IC 95\%) mediante el uso de modelos lineales generalizados. Resultados. Un total de 6322 mujeres contestaron la encuesta epidemiológica y proporcionaron muestras vaginales. La prevalencia de VB fue de 23,7\% (IC95\%: 22,6-24,7) y se asoció con tener un mayor número de parejas sexuales en los últimos 12 meses (RP: 1,22, IC 95\%: 1,03-1,44, $p=0,020$; para dos parejas y RP: 1,46, IC 95\%: 1,23-1,74, $p<0,001$ para tres o más parejas), no usar condón en la última relación sexual (RP: 1,16, IC 95\%: 1,01-1,34, $p=0,034$ ), ser residente de la sierra (RP: 1,18 , IC 95\%: 1,05-1,31, $p=0,004$ ) y tener flujo vaginal anormal o con mal olor (RP: 1,20, IC 95\%: 1,09-1,33, $p<0,001$ ). Conclusiones. La alta prevalencia de VB encontrada remarca la necesidad de fortalecer los servicios de salud para la detección y tratamiento de esta condición.

Palabras clave: Vaginosis bacteriana; Coloración de Gram; Puntaje de Nugent (fuente: DeCS BIREME).

\section{PREVALENCE OF BACTERIAL VAGINOSIS AND ASSOCIATED FACTORS IN TWENTY PERUVIAN CITIES}

\begin{abstract}
Objetives. To determine the prevalence of bacterial vaginosis (BV) and associated factors among 18-29-year-old women in 20 Peruvian cities using PREVEN project data. Materials and Methods. In this cross-sectional study, BV was defined using previously provided vaginal discharge samples on slides, which were Gram stained and observed under a microscope to determine the Nugent scores. A BV diagnosis was applied to samples with scores of 7-10. Prevalence ratios (PR) and 95\% confidence intervals $(95 \% \mathrm{Cl})$ were estimated using generalized linear models. Results. A total of 6,322 women participated in the epidemiological survey and provided vaginal swabs. The prevalence of BV was $23.7 \%$ (95\% Cl: $22.6-24.7)$ and was associated with a greater number of sexual partners in the last 12 months (PR: $1.22,95 \% \mathrm{Cl}: 1.03-1.44, p=0.020$ for two partners; PR: $1.46,95 \% \mathrm{Cl}: 1.23-1.74, p<0.001$ for three or more partners), not using a condom during last intercourse (PR: $1.16,95 \% \mathrm{Cl}: 1.01-1.34, p=0.034$ ), being a sierra resident (PR: $1.18,95 \% \mathrm{Cl}: 1.05-1.31, p=0.004)$, and having abnormal vaginal discharge or a bad smell (PR: $1.20,95 \% \mathrm{Cl}: 1.09-1.33, p<0.001)$. Conclusions. The high prevalence of BV highlights the need to strengthen health services aimed at the detection and treatment of this condition.
\end{abstract}

Key words: Bacterial vaginosis; Gram stain; Nugent score (source: MeSH NLM).

\section{INTRODUCCIÓN}

La vaginosis bacteriana (VB) es la causa más común de molestias vaginales, muy prevalente a nivel global en mujeres en edad fértil, sexualmente activas y se origina por la alteración del ecosistema de la vagina. En el mundo, el África Subsahariana registra las prevalencias más altas de VB, sobre todo en las zonas afectadas por el virus de la inmunodeficiencia humana $(\mathrm{VIH})$. En Norteamérica, una de cada tres mujeres tienen VB ${ }^{(1)}$. En Latinoamérica, Chile reporta hasta un $32 \%{ }^{(2)}$ en tanto que en adolescentes del Brasil se reportan prevalencias de más de $30 \%$, ya sea con pruebas de $\mathrm{pH}$ y $\mathrm{KOH}$, o con puntaje de Nugent ${ }^{(3)}$. En el Perú, un estudio en Lima ha reportado una prevalencia de VB de $23 \%$ en mujeres que asistieron a consultorios ginecológicos (4).

Existe controversia en si la VB es una infección de trasmisión sexual (ITS), pues algunos estudios muestran que determinados comportamientos y hábitos se asocian más frecuentemente a la VB, como por ejemplo, tener varias parejas sexuales, el sexo sin protección (sin condón), tener

\footnotetext{
Unidad de Epidemiología, ETS y VIH, Facultad de Salud Pública y Administración Carlos Vidal Layseca, Universidad Peruana Cayetano Heredia. Lima, Perú Global Health Program, Bill and Melinda Gates Foundation. Seattle, Washington, EE. UU.

School of Public Health and Community Medicine, University of Washington. Seattle, Washington, EE. UU.

Licenciado en Biología; ${ }^{\mathrm{b}}$ doctor en Epidemiología; ${ }^{\mathrm{c}}$ doctor en Ciencia Pura; ${ }^{\mathrm{d}}$ doctor en Microbiología; ${ }^{\mathrm{e}}$ doctora en Medicina

Los datos de este estudio forman parte de la tesis de Lorena López-Torres para obtener el grado de licenciada en Biología en la Universidad Nacional Federico Villarreal. Recibido: 24/08/2015 Aprobado: 01/06/2016
}

Citar como: López-Torres L, Chiappe M, Cárcamo C, Garnett G, Holmes K, García P. Prevalencia de vaginosis bacteriana y factores asociados en veinte ciudades del Perú. Rev Peru Med Exp Salud Publica. 2016;33(3):448-54. doi: 10.17843/rpmesp.2016.333.2350 
parejas sexuales mujeres (lesbianas) o realizarse duchas vaginales. Reconocer y tratar la VB es de suma importancia, pues se sabe que está asociada con problemas obstétricos y ginecológicos como parto prematuro; bajo peso al nacer, ruptura prematura de membranas, corioamnionitis, endometritis posparto, enfermedad inflamatoria pélvica o infección pélvica posquirúrgica, cervicitis y hasta infertilidad tubárica ${ }^{(5,6)}$. Adicionalmente, se ha demostrado que la VB incrementa el riesgo de adquirir otras ITS (herpes, clamidiasis, tricomoniasis, infección por virus del papiloma humano y gonorrea), incluida la infección por $\mathrm{VIH}$, para la cual casi se duplica el riesgo ${ }^{(7,8)}$

Del total de mujeres con VB, aproximadamente la mitad son sintomáticas. Estos síntomas incluyen: incremento del flujo vaginal, irritación o prurito vaginal, dispareunia (dolor con las relaciones sexuales) y un mal olor característico a pescado ${ }^{(9,10)}$. El diagnóstico de VB es complejo, pues requiere de personal bien entrenado en el uso del método clínico (criterio de Amsel) ${ }^{(11)}$ o en la aplicación del puntaje de Nugent ${ }^{(12)}$, que es la observación microscópica de morfotipos bacterianos en extendidos vaginales teñidos con coloración Gram. El puntaje de Nugent sigue considerándose como la prueba de referencia para el diagnóstico de VB por su elevada especificidad, sensibilidad y reproducibilidad. Actualmente, la VB también se puede diagnosticar con pruebas rápidas y por métodos moleculares. Sin embargo, estos métodos no son populares por su elevado costo, baja especificidad y complejidad en comparación a los tradicionales.

En el 2006, en un esfuerzo colaborativo, la Universidad Peruana Cayetano Heredia (UPCH), la Universidad de Washington y el Colegio Imperial de Londres, realizaron un ensayo aleatorizado comunitario para la prevención de ITS curables en 20 ciudades del Perú. Este proyecto llamado PREVEN (www.proyectopreven.org) incluyó la realización de encuestas, toma de muestras y pruebas de laboratorio para el diagnóstico de clamidiasis, tricomoniasis, sífilis y gonorrea, en población general peruana de 18 a 29 años. PREVEN permitió la obtención de extendidos vaginales así como encuestas a mujeres peruanas para la realización de este trabajo.

El objetivo principal del presente estudio es determinar la prevalencia de vaginosis bacteriana en mujeres de 18 a 29 años residentes en 20 ciudades del Perú, utilizando las muestras recolectadas como parte del estudio PREVEN en el año 2006. Adicionalmente, se evaluó la correlación entre los datos clínicos y de comportamiento con el diagnóstico de vaginosis bacteriana.

\section{MATERIALES Y MÉTODOS}

\section{DISEÑO DEL ESTUDIO}

Este es un estudio transversal utilizando datos del estudio PREVEN (13) diseñado como un ensayo aleatorizado en comunidades urbanas, dirigido a controlar gonorrea, clamidiasis, tricomoniasis y sífilis a través de intervenciones combinadas en 20 de las 30 ciudades con más de 50000 habitantes del Perú. Las ciudades incluidas en el estudio fueron Ayacucho, Barranca, Cajamarca, Cerro de Pasco, Chimbote, Chincha, Cusco, Huancayo, Huánuco, Huaraz, Ica, Ilo, Iquitos, Juliaca, Piura, Pucallpa, Tacna, Talara, Tarapoto, y Tumbes. La encuesta base del estudio tuvo lugar en el 2002, con posteriores mediciones en los años 2005 y 2006. Para el análisis del estudio se han utilizados los extendidos vaginales y datos más recientes, correspondientes a la encuesta del año 2006.

\section{MUESTREO Y CRITERIOS DE INCLUSIÓN}

Las ciudades seleccionadas fueron divididas en conglomerados de 40 viviendas contiguas cada una. Un total de 108 conglomerados fueron seleccionados aleatoriamente en cada ciudad. Dentro de cada conglomerado seleccionado se eligió al azar hasta diez hogares elegibles, y dentro de cada hogar una persona elegible. La selección de viviendas continuó hasta tener una muestra de 300 mujeres por ciudad.

Los criterios de inclusión fueron: mujeres de 18 a 29 años de edad, residentes en los hogares elegidos, residentes en la ciudad al menos los últimos 6 meses, capaces de responder un cuestionario además de decidir por sí misma para dar el consentimiento para su participación.

\section{RECOLECCIÓN Y TRANSPORTE DE MUESTRAS}

Después de completar el cuestionario, las encuestadoras explicaban los procedimientos para la toma de muestras vaginales autoaplicadas, guiadas por el material instructivo preparado. Solo en casos excepcionales la toma de las muestras las realizaron las encuestadoras a petición de las participantes. Al obtenerse la muestra vaginal con el hisopo, la encuestadora realizó el extendido en una lámina portaobjetos. Las láminas fueron almacenadas en cajas portaláminas y enviadas al laboratorio central en Lima.

\section{MÉTODOS EN EL LABORATORIO PARA EL DIAGNÓSTICO DE VB}

Las láminas fueron teñidas usando la tinción Gram para, finalmente, ser observadas al microscopio usando el puntaje de Nugent ${ }^{(12)}$. Se definió flora vaginal normal a aquellas láminas con puntaje de 0-3. El diagnóstico de VB se aplicó a todas las muestras con puntajes 7-10.

\section{CONSIDERACIONES ÉTICAS}

Si la persona accedía a colaborar con el estudio firmaba el consentimiento y se le realizaba la encuesta. Estas fueron hechas a través de un cuestionario en las computadoras de mano (PDA por sus siglas en inglés: Personnal Digital Assistance) y por dos métodos de entrevista: la directa, lectura de preguntas por la encuestadora y la autoaplicada, realizada por las mismas mujeres seleccionadas. Para este estudio se han seleccionado un subgrupo de preguntas como: número de relaciones sexuales en los tres últimos meses con la última pareja sexual, número de parejas en los últimos 12 meses, presencia de síntomas de ITS y el uso del condón en la última relación sexual.

\section{ANÁLISIS ESTADÍSTICO}

Se utilizó STATA 8 para Windows. Para comparar las variables nominales de las mujeres con flora normal versus las que tenían VB se utilizó la prueba exacta de Fisher. Para 
comparar las variables ordinales se utilizó el chi cuadrado para tendencia lineal. Las variables seleccionadas a priori fueron: edad actual en años (18 a 23 y 24 a 29); nivel de educación (sin estudios/primaria, secundaria y superior); estado civil (soltera, casada, conviviente y otros); número de parejas sexuales en los 12 últimos meses $(0,1,2 y \geq 3)$; el número de relaciones sexuales en los 3 últimos meses (no tuvo, 1-10, 11-20, 21-30 y 230); presencia de flujo vaginal; uso del condón en la última relación sexual, y región del Perú (costa, sierra y selva). Se estimaron razones de prevalencias (RP) y sus intervalos de confianza al 95\% (IC $95 \%$ ) mediante el uso de modelos lineales generalizados.

\section{RESULTADOS}

El estudio PREVEN incluyó una muestra aleatoria de 7087 mujeres de 18 a 29 años de edad. De estas, $765(10,8 \%)$ fueron excluidas del análisis por no haber respondido al cuestionario, porque no accedieron a realizar el hisopado vaginal, o porque no se pudo obtener un extendido adecuado para la lectura del puntaje de Nugent. De esta manera, el número de muestras incluidas en este estudio fue de 6322.

La prevalencia de VB encontrada fue de $23,7 \%$ (IC 95\%: 22,6-24,7). El promedio de edad en las mujeres con flora vaginal normal (FVN) fue de 23,4 años (desviación estándar (DE): +/-3,6) y de 23,1 años (DE: +/-3,5) en mujeres con diagnóstico de VB. Las ciudades con mayor prevalencia de VB fueron Juliaca 37,6\%; Pucallpa 33,7\%; Talara 33,5\%; Tarapoto $33,1 \%$ y Cajamarca $32,2 \%$. Las ciudades con prevalencias menores fueron Ica 10,1\%; Huánuco 12,2\%; Huaraz $13,4 \%$ e lquitos 16,8\% (Figura 1, Tabla 1).

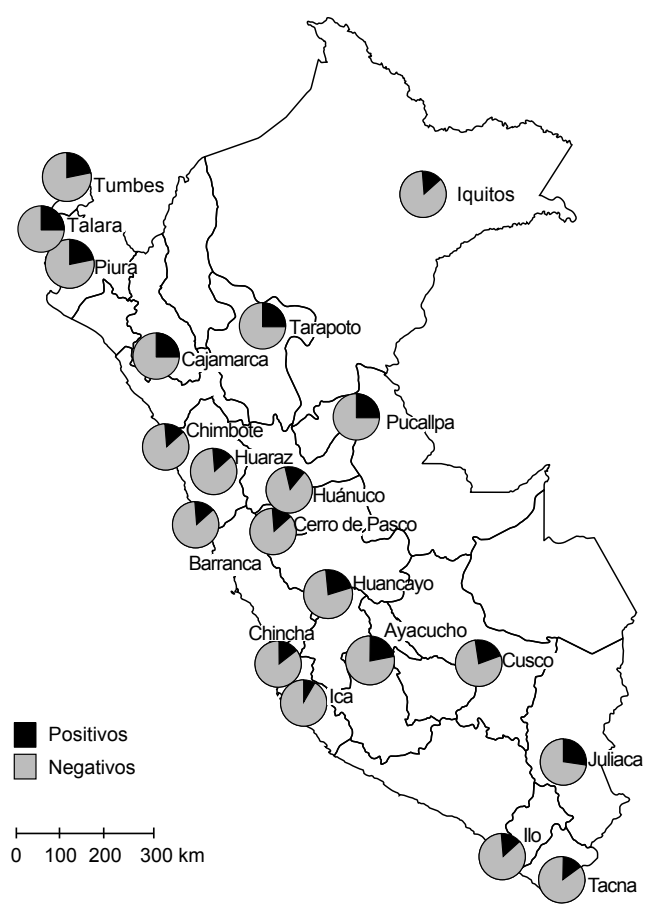

Figura 1. Prevalencia de vaginosis bacteriana según ciudades estudiadas, Perú 2006
Tabla 1. Prevalencia de vaginosis bacteriana en 20 ciudades del Perú

\begin{tabular}{|c|c|c|}
\hline Región/ Ciudad & $\begin{array}{l}\text { Positivos*I } \\
\text { Tamizados }\end{array}$ & $\begin{array}{l}\text { Prevalencia, } \\
\% \text { (IC 95\%) }\end{array}$ \\
\hline \multicolumn{3}{|l|}{ Costa } \\
\hline Barranca & $54 / 315$ & $17,1(13,0-21,3)$ \\
\hline Chimbote & $54 / 305$ & $17,7(13,4-22,0)$ \\
\hline Chincha & $63 / 298$ & $21,1(16,5-25,8)$ \\
\hline Ica & $31 / 306$ & $10,1(6,7-13,5)$ \\
\hline Ilo & $52 / 304$ & $17,1(12,8-21,4)$ \\
\hline Piura & $88 / 310$ & $28,4(23,3-33,4)$ \\
\hline Tacna & $67 / 316$ & $21,2(16,7-25,7)$ \\
\hline Talara & $121 / 361$ & $33,5(28,6-38,4)$ \\
\hline Tumbes & $91 / 314$ & $29,0(23,9-34,0)$ \\
\hline Total costa & $621 / 2828$ & $22,0(20,4-23,5)$ \\
\hline \multicolumn{3}{|l|}{ Sierra } \\
\hline Ayacucho & $93 / 320$ & $29,1(24,1-34,1)$ \\
\hline Cajamarca & $105 / 326$ & $32,2(27,1-37,3)$ \\
\hline Cerro de Pasco & $60 / 314$ & $19,1(14,7-23,5)$ \\
\hline Cusco & $75 / 303$ & $24,8(19,9-29,6)$ \\
\hline Huancayo & $75 / 310$ & $24,2(19,4-29,0)$ \\
\hline Huaraz & $44 / 329$ & $13,4(9,7-17,1)$ \\
\hline Juliaca & $115 / 306$ & $37,6(32,1-43,0)$ \\
\hline Total sierra & $567 / 2208$ & $25,7(23,9-27,5)$ \\
\hline \multicolumn{3}{|l|}{ Selva } \\
\hline Huánuco & $39 / 319$ & $12,2(8,6-15,8)$ \\
\hline Iquitos & $52 / 310$ & $16,8(12,6-21,0)$ \\
\hline Pucallpa & $106 / 315$ & $33,7(28,4-38,9)$ \\
\hline Tarapoto & $113 / 341$ & $33,1(28,1-38,2)$ \\
\hline Total selva & $310 / 1286$ & $24,1(21,8-26,4)$ \\
\hline Total & $1498 / 6322$ & $23,7(22,6-24,7)$ \\
\hline
\end{tabular}

*Score de Nugent mayor de 6

En el análisis bivariado se encontró significativamente mayor prevalencia de VB en las mujeres más jóvenes $(p=0,006)$ y no casadas $(p=0,020)$. Así mismo, se encontró más VB en mujeres con mayor número de parejas sexuales en los últimos 12 meses $(p<0,001)$ y con reporte de flujo vaginal anormal o con mal olor $(p<0,001)$. La VB fue más frecuente en quienes no usaron condón en la última relación sexual $(p=0,004)$ y residen en la región sierra $(p=0,002)$ (Tabla 2$)$.

La Tabla 3 muestra que todas las variables asociadas a mayor riesgo de VB en el análisis bivariado son predictores independientes de esta condición según el análisis multivariado. Los determinantes más importantes asociados a tener mayor prevalencia de VB fueron: tener un mayor número de parejas (RP: 1,22, IC 95\%: 1,03$1,44, p=0,020$; para dos parejas y RP: 1,46 , IC 95\%: 1,23 $1,74, p<0,001$ para tres o más parejas) y presentar flujo vaginal anormal (RP: 1,20, IC 95\%: 1,09-1,33, $p<0,001)$. 
Otras variables independientemente asociadas a mayor prevalencia fueron edad de 18-23 años (RP: 1,16, IC 95\%: 1,05-1,29, p=0,005) con respecto a 24-29 años; ser soltera (RP: 1,29, IC 95\%: 1,06-1,58, $p=0,013$ ), u otro estado marital (RP: 1,44, IC 95\%: 1,07-1,94, $p=0,018$ ) con excepción de conviviente $(p=0,131)$ con respecto a ser casada; no usar condón en la última relación sexual (RP: 1,16, IC 95\%: 1,01-1,34, p=0,034), y ser residente en la región sierra (RP: 1,18, IC 95\%: 1,05-1,31, $p=0,004)$, respecto de aquellas que viven la costa.

Tabla 2. Comparación de las características de las mujeres con flora vaginal normal (FVN) y con diagnóstico de vaginosis bacteriana (VB)

\begin{tabular}{|c|c|c|c|c|c|c|}
\hline & \multicolumn{2}{|c|}{ FVN $(n=4,824)$} & \multicolumn{2}{|c|}{ VB $(n=498)$} & \multirow{2}{*}{ RP (IC 95\%) } & \multirow{2}{*}{ Valor $p$} \\
\hline & $\mathbf{N}$ & $\%$ & $\mathbf{N}$ & $\%$ & & \\
\hline \multicolumn{7}{|l|}{ Grupos de edad } \\
\hline 18 a 23 años & 2,479 & 74,9 & 831 & 25,1 & $1,13(1,04-1,24)$ & 0,006 \\
\hline 24 a 29 años & 2,345 & 77,9 & 667 & 22,1 & 1,00 & \\
\hline \multicolumn{7}{|l|}{ Educación } \\
\hline Primaria/sin educación & 408 & 73,9 & 144 & 26,1 & 1,00 & $0,055^{*}$ \\
\hline Secundaria & 2419 & 75,9 & 770 & 24,2 & $0,93(0,80-1,08)$ & \\
\hline Superior & 1996 & 77,4 & 584 & 22,6 & $0,87(0,74-1,01)$ & \\
\hline \multicolumn{7}{|l|}{ Estado civil } \\
\hline Casada & 557 & 81,4 & 127 & 18,6 & 1,00 & \\
\hline Soltera & 2,421 & 75,4 & 792 & 24,7 & $1,33(1,11-1,59)$ & 0,002 \\
\hline Conviviente & 1,723 & 76,8 & 520 & 23,2 & $1,25(1,04-1,51)$ & 0,020 \\
\hline Otros & 121 & 67,9 & 57 & 32,0 & $1,72(1,33-2,24)$ & $<0,001$ \\
\hline $\mathrm{N} .^{\circ}$ de parejas en los últimos doce meses & & & & & & $<0,001^{*}$ \\
\hline 0 & 1364 & 77,7 & 390 & 22,2 & 1,00 & \\
\hline 1 & 1909 & 76,4 & 591 & 23,6 & $1,06(0,95-1,19)$ & \\
\hline 2 & 306 & 71,2 & 124 & 28,8 & $1,29(1,09-1,53)$ & \\
\hline$\geq 3$ & 175 & 64,3 & 97 & 35,7 & $1,60(1,35-1,89)$ & \\
\hline $\begin{array}{l}\mathrm{N} .{ }^{\circ} \text { de relaciones sexuales en los tres últi- } \\
\text { mos meses }\end{array}$ & & & & & & $0,270^{*}$ \\
\hline Ninguna & 644 & 75,7 & 207 & 24,3 & 1,00 & \\
\hline $1-10$ & 1823 & 75,7 & 586 & 24,3 & $1,00(0,87-1,15)$ & \\
\hline $11-20$ & 468 & 76,2 & 146 & 23,8 & $0,98(0,81-1,18)$ & \\
\hline $21-30$ & 161 & 73,9 & 57 & 26,2 & $1,08(0,84-1,38)$ & \\
\hline$>30$ & 213 & 72,2 & 82 & 27,8 & $1,14(0,92-1,41)$ & \\
\hline \multicolumn{7}{|l|}{$\begin{array}{l}\text { Flujo vaginal anormal abundante o con mal } \\
\text { olor }\end{array}$} \\
\hline No & 3105 & 78,4 & 858 & 21,7 & 1,00 & \\
\hline Sí & 1664 & 72,6 & 627 & 27,4 & $1,26(1,16-1,38)$ & $<0,001$ \\
\hline \multicolumn{7}{|l|}{ Usó condón en la última relación sexual } \\
\hline Sí & 684 & 78,4 & 189 & 21,7 & 1,00 & \\
\hline No & 3086 & 74,9 & 1031 & 25,0 & $1,16(1,00-1,33)$ & 0,044 \\
\hline \multicolumn{7}{|l|}{ Región } \\
\hline Costa & 2207 & 78,0 & 621 & 21,9 & 1,00 & \\
\hline Sierra & 1641 & 74,3 & 567 & 25,7 & $1,17(1,06-1,29)$ & 0,002 \\
\hline Selva & 976 & 75,9 & 310 & 24,1 & $1,10(0,97-1,24)$ & 0,127 \\
\hline
\end{tabular}

* Chi-cuadrado para tendencia lineal. 
Tabla 3. Modelo multivariado de las características asociadas a vaginosis bacteriana

\begin{tabular}{|c|c|c|c|}
\hline & RP & (IC 95\%) & Valor $p$ \\
\hline \multicolumn{4}{|l|}{ Grupos de edad } \\
\hline 18 a 23 & 1,16 & $(1,05-1,29)$ & 0,005 \\
\hline 24 a 29 & 1,00 & & \\
\hline \multicolumn{4}{|l|}{ Estado civil } \\
\hline Casada & 1,00 & & \\
\hline Soltera & 1,29 & $(1,06-1,58)$ & 0,013 \\
\hline Conviviente & 1,17 & $(0,96-1,43)$ & 0,131 \\
\hline Otros & 1,44 & $(1,07-1,94)$ & 0,018 \\
\hline \multicolumn{4}{|l|}{$\begin{array}{l}\mathrm{N} .^{\circ} \text { de parejas en los } \\
\text { últimos } 12 \text { meses }\end{array}$} \\
\hline 0 & 1,00 & & \\
\hline 1 & 1,02 & $(0,91-1,15)$ & 0,706 \\
\hline 2 & 1,22 & $(1,03-1,44)$ & 0,020 \\
\hline$\geq 3$ & 1,46 & $(1,23-1,74)$ & $<0,001$ \\
\hline $\begin{array}{l}\text { Flujo vaginal anormal } \\
\text { abundante o con mal olor }\end{array}$ & 1,20 & $(1,09-1,33)$ & $<0,001$ \\
\hline $\begin{array}{l}\text { No usó de condón en la } \\
\text { última relación sexual }\end{array}$ & 1,16 & $(1,01-1,34)$ & 0,034 \\
\hline \multicolumn{4}{|l|}{ Región } \\
\hline Costa & 1,00 & & \\
\hline Sierra & 1,18 & $(1,05-1,31)$ & 0,004 \\
\hline Selva & 1,05 & $(0,92-1,19)$ & 0,513 \\
\hline
\end{tabular}

\section{DISCUSIÓN}

Uno de los objetivos de este estudio fue determinar la prevalencia de vaginosis bacteriana (VB) en la población general de mujeres peruanas de 18-29 años de edad en 20 ciudades del Perú y su asociación con comportamiento sexual y hallazgos clínicos. El presente es un estudio único en el Perú y el mundo, por ser el primero en incluir muestras representativas de 20 ciudades, obtenidas por muestreo aleatorio con base poblacional.

La prevalencia de VB encontrada en este estudio fue de $23,7 \%$, porcentaje muy similar al reportado por Medina et al. $(23,24 \%)$ en 370 mujeres atendidas en consultorios ginecológicos, y menor a lo encontrado por Jones et al. en Lima (27\%) en mujeres de poblaciones socioeconómicamente desfavorecidas, ${ }^{(14)}$ y por García et al. $(39 \%)$ en un mujeres que acuden a farmacias ${ }^{(15)}$. Es bien conocido que la prevalencia de VB varía de acuerdo al tipo de población estudiada y según la metodología de diagnóstico empleada; por ejemplo, Perla et al. (2012) encontraron una prevalencia de $44,8 \%$ en 212 trabajadoras sexuales ${ }^{(16)}$. García et al. (2004) encontraron prevalencia de $43,7 \%$ en mujeres de áreas rurales de 18-67 años en las tres regiones del Perú ${ }^{(17)}$. Por otro lado, Marazzo et al. reportaron una prevalencia de VB de $29 \%$ en mujeres que tienen sexo con otras mujeres ${ }^{(18)}$.

Mundialmente se reportan prevalencias altas en África subsahariana, tal como se muestra en un metaanálisis de más de 170 estudios, en el que la prevalencia de VB en el sur y oriente de África fue de 50,8\% (43,3-58,4\%), y en el centro y occidente de África fue de $37,6 \%(18,0-$ $57,2 \%)^{(19)}$. En los EE.UU., en una muestra representativa de 3739 mujeres reclutadas durante 2001-2004 a nivel nacional, casi una de cada tres participantes $(29,2 \%$; IC $95 \%$ 27,2-31,3) tenía VB por tinción de Gram del líquido vaginal (1). En Chile se reportaron prevalencias entre 27 y $32 \%{ }^{(2)}$. La alta prevalencia detectada en nuestro estudio resulta muy superior a la detectada en países de Europa y similar a las detectadas en EE.UU. y otros países de Latinoamérica.

En el presente estudio la prevalencia de VB es mayor en mujeres más jóvenes, no casadas, con más parejas sexuales y que no usan condón. Es conocido que el rol de las relaciones sexuales contribuye, al menos en algunas mujeres, al cambio de una vagina saludable a aquella colonizada por comunidades complejas de bacterias. En este estudio hemos encontrando que la prevalencia de VB mayor en quienes tienen más parejas en los últimos 12 meses. Esto confirma lo encontrado en la literatura ${ }^{(20)}$. Podría pensarse que las mujeres jóvenes y solteras tienen mayor número de parejas sexuales, y esto explicaría el hallazgo de mayor prevalencia en mujeres más jóvenes. Sin embargo, el análisis multivariado muestra que esta asociación persiste luego de controlar por las otras variables independientemente asociadas a VB: número de parejas, estado civil y región.

Un hallazgo consistente con otros estudios ${ }^{(20)}$ es que la prevalencia de VB es mayor cuando no hay uso de condón en la última relación sexual (indicador de uso inconsistente del condón). Esto se podría deber a que el semen contribuye a la eliminación de FVN y al desarrollo de VB ${ }^{(21,22)}$.

La literatura reporta que casi el $50 \%$ de mujeres que tienen VB presentan síntomas ${ }^{(10)}$. Uno de estos síntomas es el típico flujo vaginal anormalmente abundante y de muy mal olor. Nuestro estudio muestra que es más frecuente el diagnóstico de VB cuando las mujeres reportan esta sintomatología clínica. La formación del flujo anormal se debe a la degradación de la mucina en la vagina gracias a las enzimas producidas por las bacterias anaerobias Gram negativas. El mal olor, descrito como "olor a pescado" se debe a la volatilización de las aminas producidas por el metabolismo de las bacterias anaeróbicas ${ }^{(8-10)}$.

Un hallazgo interesante fue encontrar mayor prevalencia de VB en mujeres residentes de la sierra. Se esperaba encontrar mayor prevalencia de VB en mujeres de la selva, pues se reporta mayor prevalencia de ITS en esa región. Esto podría explicarse por algunos aspectos relacionados a prácticas de "higiene" vaginales (que no se exploraron), el uso de productos intravaginales $u$ hormonales o tal vez a otros factores biológicos particulares en estas mujeres. Es 
conocido que los lavados vaginales están asociados a un riesgo incrementado de $\mathrm{VB}^{(23)}$ y existen prácticas tradicionales no documentadas de higiene vaginal en población andina.

Como el estudio es un análisis secundario de datos a partir del Proyecto PREVEN, una de nuestras limitaciones es que el cuestionario no contemplaba preguntas sobre el uso de duchas vaginales, dispositivos intrauterinos, hormonas contraceptivas, uso de tabaco, periodo menstrual y estrés crónico, que son actualmente considerados como factores de riesgo para VB.

El proyecto PREVEN, por haber sido un estudio aleatorizado realizado en población urbana en 20 ciudades del Perú, nos da resultados con menor posibilidad de sesgo y que puedan ser reproducibles y comparables con otros estudios.

En vista de la alta prevalencia de VB en las mujeres peruanas, es importante que el profesional de salud esté alerta a esta enfermedad muchas veces asintomática, para prevenir complicaciones como: parto prematuro, ruptura prematura de membranas, enfermedad inflamatoria pélvica, cervicitis y riesgo de adquirir otras ITS. Se recomienda focalizar los esfuerzos para el control de esta condición en poblaciones de mayor riesgo, es decir, mujeres jóvenes y no casadas de la sierra, y tratar de incidir sobre factores de riesgo modificables, como número de parejas sexuales y el uso de condón.

Contribuciones de los autores: LLT ha participado en la recolección, obtención de resultados y redacción del artículo. MC realizo la revisión crítica del artículo; CC realizó el análisis e interpretación de datos y su aprobación de su versión final; GG y KH han participado en la concepción del estudio original. PG ha participado en la revisión crítica del artículo y Aprobación de su versión final.

Fuente de financiamiento: el proyecto fue financiado por el Wellcome Trust and Burroughs Wellcome Fund y Center for AIDS Research.

Conflictos de interés: los autores declaran no tener conflictos de interés en la publicación de este artículo.

\section{REFERENCIAS BIBLIOGRÁFICAS}

1. Koumans EH, Sternberg M, Bruce C, McQuillan G, Kendrick J, Sutton $\mathrm{M}$, et al. The prevalence of bacterial vaginosis in the United States, 20012004; associations with symptoms, sexual behaviors, and reproductive health. Sex Transm Dis. 2007;34(11):864-9.

2. Lillo GE, Lizama I, Medel C, Martinez T. Diagnosis of bacterial vaginosis in women attending a family planning clinic in the Metropolitan Region of Chile. Rev Chilena Infectol. 2010;27(3):199-203. doi: /S0716-10182010000300002.

3. Campos AA, Leite AP, Lisboa CV, Andrade CC, Bezerra AF, Mattar R, et al. Comparative study between the $\mathrm{pH}$ test and of the $\mathrm{KOH}$ versus Nugent score for diagnosis of bacterial vaginosis in pregnant women. Rev Bras Ginecol Obstet. 2012;34(5):209-14.

4. Medina G, Rechkemmer P, GarciaHjarles M. Prevalencia de vaginitis y vaginosis bacteriana en pacientes con flujo vaginal anormal en el Hospital Nacional Arzobispo Loayza Lima Perú. Rev Med Hered. 1999;10(4):144-50.

5. Gonzales-Pedraza A, Ortiz C, Dávila R, Valencia C. Infecciones cervicovaginales más frecuentes, Prevalencia y Factores de Riesgos. Rev Cubana Obstet Ginecol. 2007;33(2):1-12.

6. Gillet E, Meys JF, Verstraelen H, Verhelst $\mathrm{R}$, De Sutter P, Temmerman M, et al.
Association between Bacterial Vaginosis and Cervical Intraepithelial Neoplasia: Systematic Review and Meta-Analysis. PLoS One. 2012. 7(10):e45201. doi: 10.1371/journal.pone.0045201.

7. Cohen CR, Lingappa JR, Baeten JM, Ngayo MO, Spiegel CA, Hong T, et al. Bacterial Vaginosis Associated with Increased Risk of Female-to-Male HIV1 Transmission: A Prospective Cohort Analysis among African Couples. PLoS Med. 2012;9(6):e1001251. doi: 10.1371/journal.pmed.1001251.

8. Caballero R, Batista R, Cue M, Ortega L, Rodriguez M. Vaginosis bacteriana. RESUMED. 2000;13(2):63-75.

9. Hillier $S$, Holmes K. Sexually Transmitted Diseases. 2nd ed. New York: McGraw-Hill; 1990.

10. Morse $S$, Holmes K. Vaginal infections. In Atlas of Sexually Transmitted Diseases and AIDS. 2nd ed. London: Elsevier Limited; 1996.

11. Amsel R, Totten PA, Spiegel CA, Chen KC, Eschenbach D, Holmes KK. Nonspecific vaginitis. Diagnostic criteria and microbial and epidemiologic associations. Am J Med. 1983;74(1):14-22.

12. Nugent RP, Krohn MA, Hillier SL. Reliability of diagnosing bacterial vaginosis is improved by a standardized method of gram stain interpretation. J Clin Microbiol. 1991;29(2):297-301.

13. García PJ, Holmes KK, Cárcamo CP, Garnett GP, Hughes JP, Campos PE, et al. Prevention of sexually transmitted infections in urban communities (Peru PREVEN): a multicomponent community-randomized controlled trial. The lance 2012;379(9821):1120-8. doi: 10.1016/S0140-6736(11)61846-1.

14. Jones FR, Miller G, Gadea N, Meza $\mathrm{R}$, Leon S, Perez J, et al. Prevalence of bacterial vaginosis among young women in low-income populations of coastal Peru. Int J STD AIDS. 2007;18(3):188-92.

15. Garcia PJ, Cárcamo CP, Chiappe $\mathrm{M}$, Holmes KK. Sexually transmitted and reproductive tract infections in symptomatic clients of pharmacies in Lima, Peru Sex Transm Infect. 2007;83(2):142-6.

16. Perla ME, Ghee AE, Sanchez $S$, McClelland RS, Fitzpatrick AL, Suarez-Ognio L, et al. Genital Tract Infections, Bacterial Vaginosis, HIV, and Reproductive Health Issues among Lima-Based Clandestine Female Sex Workers. Infect Dis Obstet Gynecol. 2012;2012:739624. doi: $10.1155 / 2012 / 739624$.

17. Garcia PJ, Chávez S, Feringa B, Chiappe M, Li W, Jansen KU et al. Reproductive 
tract infections in rural women from the highlands, jungle, and coastal regions of Peru. Bull World Health Organ. 2004;82(7):483-92.

18. Marrazzo JM, Koutsky LA, Eschenbach DA, Agnew K, Stine K, Hillier SL. Characterization of vaginal flora and bacterial vaginosis in women who have sex with women. J Infect Dis. 2002;185(9):1307-13.

19. Chico RM, Mayaud P, Ariti C, Mabey D, Ronsmans C, Chandramohan D. Prevalence of malaria and sexually transmitted and reproductive tract infections in pregnancy in sub-Saharan Africa: a systematic review. JAMA. 2012;307(19):2079-86. doi: 10.1001/ jama.2012.3428.
20. Fethers KA, Fairley CK, Hocking JS, Gurrin LC, Bradshaw CS. Sexual Risk Factors and Bacterial Vaginosis: A Systematic Review and Meta-Analysis. Clin Infect Dis. 2008;47(11):1426-35. doi: $10.1086 / 592974$.

21. Gallo MF, Warmer L, King CC, Sobel JD, Klein R, Cu-Uvin S, et al. Association between semen exposure and incident bacterial vaginosis. Infect Dis Obstet Gynecol. 2011;2011:842652. doi: $10.1155 / 2011 / 842652$.

22. Nurris Turner A, Carr Reese P, Snead MC, Fields K, Ervin M, Kourtis AP, et al. Recent Biomarker-Confirmed Unprotected Vaginal Sex, But Not Selfreported Unprotected Sex, Is Associated With Recurrent Bacterial Vaginosis. Sex
Transm Dis. 2016;43(3):172-6. doi: 10.1097/OLQ.0000000000000414.

23. Klebanoff MA, Nansel TR, Brotman RM, Zhang J, Yu KF, Schwebke JR, et al. Personal hygienic behaviors and bacterial vaginosis. Sex Transm Dis. 2010;37(2):94-9. doi: 10.1097/ OLQ.0b013e3181bc063c.

Correspondencia: César Cárcamo Cavagnaro Dirección: Facultad de Salud Pública y Administración Carlos Vidal Layseca. Universidad Peruana Cayetano Heredia Av. Honorio Delgado 430 Urb. Ingeniería, Lima 31, Perú.

Teléfono: 997350773, 319-0028

Correoelectrónico:cesar.carcamo@upch.pe

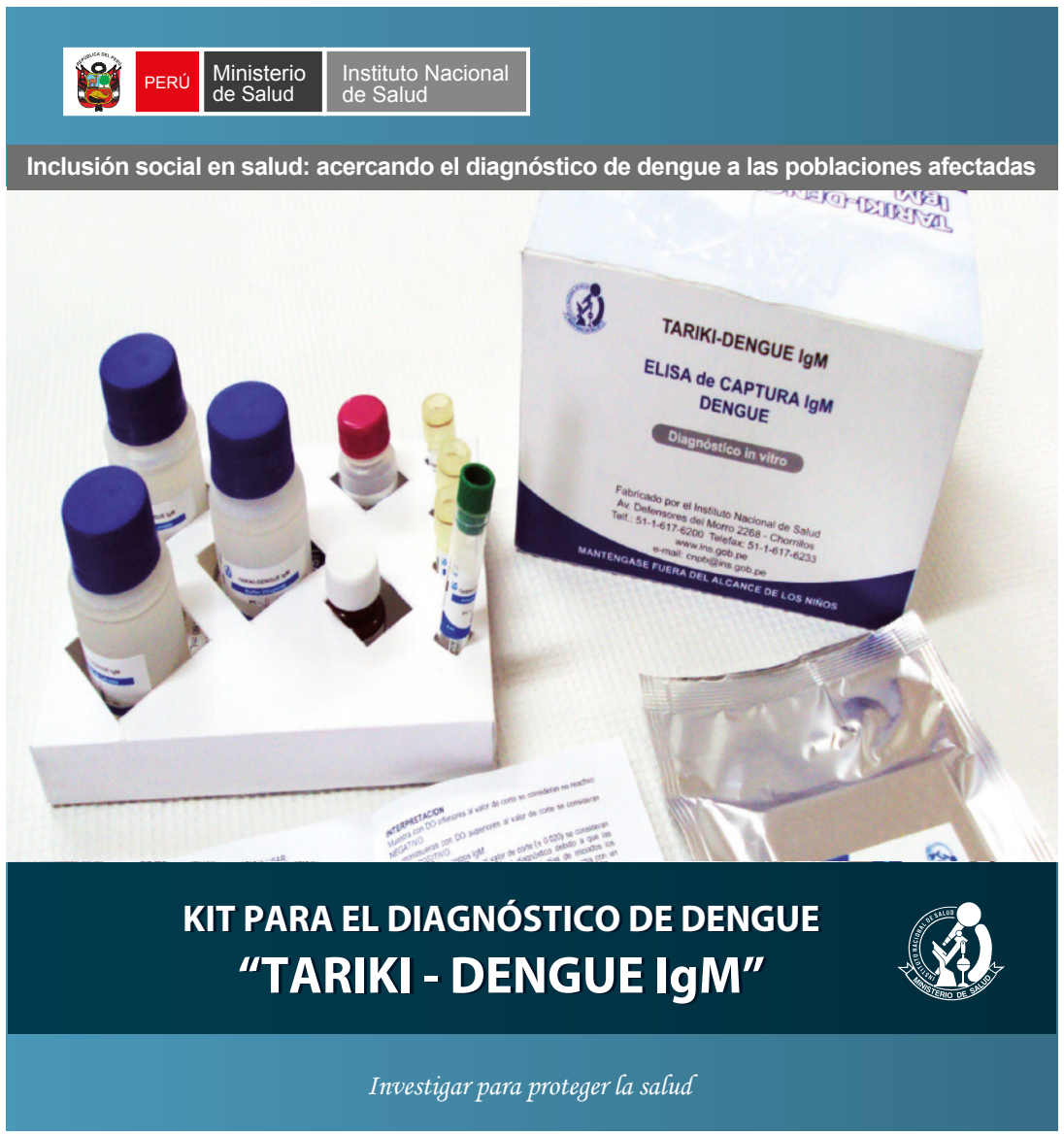

